\section{Risk management strategies following analysis of cataract negligence claims}

A Bhan', D Dave², SA Vernon'1, K Bhan'1, J Bhargava' and H Goodwin ${ }^{3}$
${ }^{1}$ Queens Medical Centre Nottingham, UK

${ }^{2}$ Chesterfield Royal Hospital Chesterfield, UK

${ }^{3}$ Medical Defence Union, London, UK

Correspondence: A Bhan Department of Academic Ophthalmology B Floor, Queens Medical Centre

Nottingham NG7 2UH

Tel: +441159249924 ext 43853

Fax: +44 1159709963

E-mail:

archanab@tiscali.co.uk

Received: 9 September 2003 Accepted: 4 December 2003 Published online: 30 July 2004

In conjunction with the Medical Defence Union, Medical Protection Society, and the Medical and Dental Defence Union of Scotland
Abstract

Introduction Clinical governance and risk management is very important in today's clinical practice. Cataract surgery is one of the most common procedures performed in the NHS, with around 200000 operations per year. In order to help minimise the frequency of negligence claims, we performed a collaborative study to analyse claims relating to cataract surgery, dealt with by the defence organisations of England, Scotland, Wales, and Northern Ireland.

Materials and Methods All claims dealt with by the Medical Defence Union, the Medical Protection Society, and the Medical and Dental Defence Union of Scotland from January 1990 to December 1999, were analysed by three ophthalmologists with at least 5 years' speciality experience. Recurrent themes were identified and claims were grouped by major causative factor. The findings were discussed by a panel comprising the authors in conjunction with the defence unions and risk management strategies were designed.

Results There were 96 claims within the 10- year period analysed. Of these, the largest group (52) pertained to claims that related to accepted complications of cataract surgery. The remainder comprised two groups: 'Medical Errors' (anaesthetic, surgeon, and biometry) and 'Other Claims' comprising subjective complaints, pain and poor visual outcome. A total of 16 claims had been settled by May 2002, 45 are ongoing and 35 have closed without settlement.

Conclusions The majority of claims pertained to well-recognised complications of cataract surgery. If these risks are adequately explained to the patient before surgery and if the care provided reaches a standard acceptable to a responsible body of professional opinion, all such claims should be defensible. Good visual outcome does not protect against litigation.

Eye (2005) 19, 264-268. doi:10.1038/sj.eye.6701493

Published online 30 July 2004

Keywords: cataract; surgery; complications; review; medico legal

Introduction

Clinical governance issues have become a regular feature in discussions concerning patient care. One very important aspect of this is clinical risk reduction or risk management where one takes account of adverse events and complaints in order to learn lessons, and ultimately improve the delivery of care to patients. Cataract surgery is one of the most common elective procedures performed in the United Kingdom, accounting for around 200000 NHS cataract operations per year. ${ }^{1}$ Although the risk of a significant adverse incident occurring during or after cataract surgery is low, ${ }^{2}$ the numbers of cases operated on per year results in a significant number of claims. Each claim occupies medical, secretarial, and managerial time, and may cause considerable stress for those defending, and probably making the claim.

In order to develop an evidence-based risk management strategy to help minimise the frequency of negligence claims following cataract surgery, we performed a collaborative study to analyse claims relating to cataract surgery, dealt with by the defence organisations of England, Scotland, Wales, and Northern Ireland.

\section{Methods}

All claims dealt with by the Medical Defence Union, the Medical Protection Society, and the Medical and Dental Defence Union of Scotland over a 10-year period, from January 1990 to 
December 1999, were analysed by two ophthalmologists with at least 5 years' speciality experience. The data were anonymised and then recorded on a computerised database. The data were extracted from the copies of medical records held and from other documents such as medical reports, relating to the claims. Although each case was unique, and dependent on a number of variables, some recurrent themes were identified. Claims were grouped by the reason for the claim and the findings were then discussed by a panel comprising the authors, and risk management strategies designed. These were then approved by all the defence organisations involved.

\section{Results}

In total, there were 96 claims within the 10-year period analysed (Table 1). Of these 96 cases, the largest group (52) pertained to 'Consent Issues', that is, claims that related to recognised complications of cataract surgery, which we considered should have been avoidable if there had been adequate informed consent. The remainder comprised two groups: 'Medical Errors' (a combination of error and alleged errors pertaining to the anaesthetic, surgeon, and biometry), and 'Other Claims' comprising subjective complaints, pain, and poor visual outcome. Overall, 16 claims had been settled by May 2002 although several claims are still ongoing. In all, 35 cases have been closed without settlement.

\section{Consent issues}

Posterior capsule rupture

A total of 22 patients had the intraoperative surgical complication of posterior capsule rupture resulting in

Table 1 Analysis of claims relating to cataract surgery over a 10-year period

\begin{tabular}{lc}
\hline Causes & Claims \\
\hline Consent Issues & \\
$\quad$ Posterior capsule & 22 \\
tears/vitreous & \\
loss/retained nucleus & \\
$\quad$ Endophthalmitis & 16 \\
Corneal decompensation & 8 \\
$\quad$ Expulsive/suprachoroidal haemorrhage & 6 \\
Anaesthetic error & 11 \\
Surgeon error & 9 \\
Biometry/IOL error & 9 \\
Subjective complaints & 6 \\
Poor visual outcome & 6 \\
Pain & 4 \\
\hline
\end{tabular}

variable outcomes, with the final visual outcome (FVO) in this group ranging from 6/9 to perception of light (PL), with a median of $6 / 18$. There was documentation of an immediate explanation to the patient (defined as within 2 days of surgery) in eight cases, a delayed explanation in two cases, and no clear documentation in 12 cases. Two cases were settled, 11 closed without settlement, two were dropped, and seven are ongoing.

\section{Endophthalmitis}

In total, 16 cases of endophthalmitis (postoperative intraocular infection) stimulated claims. The FVO ranged from $6 / 6$ to no perception of light (NPL). Of the 16 eyes, 12 had 6/60 vision or worse. One case was settled, five closed without settlement, and the remainder are ongoing. In only nine of the 16 cases was there documentation of an explanation to the patient of the complication. In two cases, there was no documented recognition of the endophthalmitis. The management of endophthalmitis was noticeably very variable prior to the introduction of guidelines by the Royal College of Ophthalmologists in 1996. After this date, all surgeons followed the recommendations in the guidelines.

\section{Suprachoroidal/expulsive haemorrhage}

Six patients claimed following a severe intraoperative haemorrhage. There was recognition and documentation of the complication in all cases. In all but one case, there was documentation of steps taken to manage the complication, but in only two cases was there a documentation of an explanation to the patient. The FVO ranged from 6/18 to NPL, with four cases resulting in NPL. To date, three claims have closed without settlement, two have been discontinued, and one is going on.

\section{Corneal decompensation}

Eight patients claimed because of poor vision due to corneal clouding postoperatively as a result of surgically induced corneal decompensation. There was a documented explanation about the complication to the patient in only two cases. Two cases have been settled, three closed without settlement, one discontinued, and two are going on. In one case, a full and detailed explanation including written correspondence to the patient led to a resolution of the claim. The FVO ranged from 6/9 to counting fingers (CF), the good acuity being associated with corneal transplantation. One case was found to be associated with a corneal endothelial dystrophy, but this risk factor, which is known to predispose to corneal decompensation, was not documented preoperatively. 


\section{Medical Errors}

\section{Anaesthetic error}

Of a total of 11 claims, nine related to perforation of the globe during local anaesthetic blocks for the surgery. To date, five claims have been discontinued and the remainder have no data on outcome. Documentation of an explanation to the patient was made in two cases on the first postoperative day, later than this in five cases, and in two cases no explanation was documented. In one of these two cases, there was not even documentation of recognition of the complication. All blocks were performed by anaesthetists and all claims following perforation were associated with a sharp needle technique of regional anaesthesia. Five of the nine patients required subsequent retinal detachment surgery and FVO varied from 6/18 to NPL.

There were two claims relating to other anaesthetic problems; one claim was as a result of ocular complications secondary to suboptimal general anaesthesia (settled), and one claim related to inadequate pain relief following local anaesthetic that led to surgical complications (not settled to date).

\section{Surgeon Error}

Nine claims resulted from direct surgeon error either in preoperative, intraoperative, or postoperative care. Six cases were settled, one case closed without settlement, and two have not been settled to date. The FVO in this group ranged from 6/9 to PL. In eight out of nine cases, it appeared that recognition and documentation of complications, with appropriate steps taken to manage them, had occurred. Two cases related to the routine use of surgical techniques considered outdated at the time. In one case, a patient who was known to be allergic to penicillin was given both flucloxacillin and ampicillin.

\section{Biometry/IOL Errors}

Nine patients initiated claims in this group in which the optical situation following surgery fell short of what might be expected in normal practice. Four claims were settled, four closed without settlement and one has not been settled to date. The FVO ranged from $6 / 6$ to $6 / 36$ with a median of $6 / 12$. In only four cases was there evidence that an explanation of the reason(s) for the error had been made to the patient. In five cases, the biometry process was considered to be at fault, with an outdated power calculation formula used in one of these, but in the sixth an inadvertent incorrect interpretation by the surgeon had been made of a biometry process considered to be satisfactory.

\section{Other claims}

\section{Subjective complaints}

Six patients had subjective complaints considered to be minor in nature. To date, four have closed without settlement and two are going on. There was documentation of an explanation to the patient in two cases, but it was absent in the remainder. Interestingly, two patients complained because they felt they were not told that they would need glasses postoperatively and one because they had broken sutures that required removal.

Poor visual outcome

Six patients complained primarily due to poor visual outcome. The best-corrected visual acuity (BCVA) ranged from 6/9 to 6/60. A documented explanation was not found in three cases, with insufficient data to comment on the remaining three cases. One case was settled, one discontinued, and three are going on. Recognition and documentation of complications occurred in only one case.

\section{Pain}

Four patients registered claims due to excessive pain (three intraoperatively and one postoperatively). To date, two cases have closed without settlement and two are still going on.

\section{Discussion}

For the 10-year period studied, 96 cases may appear to be a small number of claims. Following the introduction of NHS indemnity in 1990 however, all NHS claims have been processed by the NHS Litigation Authority and we were not permitted access to these details. This present study thus deals only with claims resulting from operations performed on private patients. It is difficult to estimate the number of cataract procedures undertaken privately in the UK to act as a denominator for this study. A postal survey undertaken by us of consultant ophthalmologists in the Trent region with a 55\% response rate, showed that it is likely that each consultant operated on a mean number of approximately 60 cases in the year 2000. If this pattern was similar across the UK, then one could estimate that there may be approximately 4000 private cases undertaken annually. There have been analyses of overseas medicolegal claims published, ${ }^{3-8}$ but to our knowledge, this is the first study of its kind from the UK.

The majority of cases pertained to well-recognised complications of cataract surgery that could happen to any competent surgeon. However, patients must be given 
enough information to make an informed choice about whether to accept treatment or not. Failure to do so may constitute a breach of duty of care. Should a claim arise, the standard by which an individual doctor is judged against is one known as the Bolam principle, namely, whether the care provided reached a standard acceptable to a responsible body of his or her peers and that it had a 'logical basis' (the Bolitho Judgment).

In order for a claimant to be successful in a consent claim, it is important to ask 'would the claimant have undergone the procedure had they been adequately warned?' If the answer is yes, no cause of action will arise even if a complication arises, provided that complication is managed appropriately. If the claimant can establish that they would not have had the operation, then the issue is one of quantum. That is assessing the difference between the patient's condition with surgery and without and then calculating an award of damages based upon this difference.

A vital source of evidence will be the existence of documentation of explanations given prior to surgery and whether consent was sought and documented. It is important to note that even if you have explained and documented every known complication within the records, you have signed written consent and given the patient information literature, if a complication is not managed to a standard comparable to that of a responsible body of doctors practising in the same field, then you could still be considered negligent.

It is clear from the results of this study that a relatively good visual outcome does not protect against potential litigation. Indeed $28 \%$ of these cases resulted in a best corrected acuity of $6 / 12$ or better being achieved, the level of vision used as standard in the National Cataract Audit. $^{2}$ It is possible that alternative assessors might have recategorised some claims in this study. In all cases of overlapping or uncertain category, consensus opinion was gained prior to a final decision on categorisation being made. The following risk management strategies were devised and agreed as a result of examination of the results of this study.

\section{Preoperative assessment and consent}

- Document complete examination including indications for surgery as well as type of surgery and that the patient would like to proceed with surgery.

- List the complications and unexpected results in information given prior to signing consent.

- Document that the patient has received the above information.

- Document that the patient understands the potential complications of the procedure and the expected outcomes including the likelihood of postoperative spectacle correction. The anecdotal notion that it is not necessary to tell a patient about a complication if it has a less than $1 \%$ chance of happening, is incorrect.

- Use appropriate contemporary lens power calculation formulae.

- Document the reasons for the choice of IOL preoperatively, preferably after discussion of the possible refractive outcomes with the patient, prior to the final consent process.

- Consent your own patients or if delegating the task, ensure that your colleague has the necessary understanding of the procedure planned, and of what to advise the patient.

\section{Surgery}

- Use a preoperative checklist that could contain the patients' name, date of birth, the site of the operation, operation plan including the IOL power and known allergies to devices or drugs.

- Use. up-to-date techniques comparable to the most recent National Cataract Audit.

- Use a tick sheet for the operation note to ensure all steps are documented while saving notation time.

- If a different IOL was used in the procedure than that planned, explain this to the patient and document why.

- If a complication occurs, document its recognition and management.

\section{Endophthalmitis}

Most claims related to delayed diagnosis and failure to treat aggressively.

- Follow the Royal College of Ophthalmologists' guidelines unless you have good reason to do otherwise. If you do not follow the guidelines, document why.

- Document the use of any prophylactic antibiotics (this could be incorporated into a prewritten operation note) and ensure adequate notation to justify clinical decisions.

\section{General}

- Never alter notes.

- Make sure that there is a good complaints procedure in place in your department/hospital, which includes writing to the patient if necessary, and freely agreeing to meet with the patient and relatives with mediators if needed. 
- Do not delay an explanation of an unexpected outcome.

- Try to ensure good communication at all times, as poor communication compromises patient care.

- Apologising to the patient for undue distress is not an admission of liability.

\section{References}

1 NHS Executive. Action on cataracts. NHS Executive, Department of Health, UK,, January 2002.

2 Desai P, Minassian DC, Reidy A. National cataract surgery survey 1997-8: a report of the results of the clinical outcomes. Br J Ophthalmol 1999; 83(12): 1336-1340.
3 Bettman JW. A review of 412 claims in ophthalmology. Int Ophthalmol Clinics 1979; 20: 131-142.

4 Bettman JW. A retrospective look at twenty-two medicolegal claims. How they might have been avoided. Surv Ophthalmol 1983; 28: 55-60.

5 Kraushar MF, Turner MF. Medical malpractice litigation in cataract surgery. Arch Ophthalmol 1987; 105: 1339-1343.

6 Bettman JW. Seven hundred medicolegal cases in ophthalmology. Ophthalmology 1990; 97: 1379-1384.

7 Kraushar MF, Robb JH. Ophthalmic malpractice lawsuits with large monetary awards. Arch Ophthalmol 1996; 114: 333-337.

8 Brick DC. Risk management lessons from a review of 168 cataract surgery claims. Surv Ophthalmol 1999; 43: 356-360. 